\title{
Heterobimetallic Mn/Co hybrid complexes composed of proximate organometallic and classical coordination sites
}

\author{
Huaxin Zhang a, Sebastian Dechert a , Jörg Maurer ${ }^{\text {b }}$, Michael Linseis ${ }^{\text {b }}$, \\ Rainer F. Winter ${ }^{b}$, Franc Meyer ${ }^{\text {a,* }}$ \\ ' Institut für Anorganische Chemie, Georg-August-Universität Göttingen, Tammanstraße 4, D-37077 Göttingen, Germany' \\ ${ }^{\mathrm{b}}$ Institut fïr Anorganische Chemie, Universität Regensburg, Universitätsstraße 31, D-93040 Regensburg, Germany
}

\begin{abstract}
A series of highly unsymmetric heterobinuclear $\mathrm{Mn} / \mathrm{Co}$ complexes is reported, in which an organometallic $\mathrm{CpMn}(\mathrm{CO})_{2}$ fragment and a classical Werner-type cobalt(II) subunit are arranged in close proximity by means of a bridging pyrazolate. Two ligand scaffolds are employed that differ by the chelate size of the tripodal tetradentate $\{\mathrm{N} 4\}$ binding site for cobalt. Molecular structures of three complexes with either nitrate or acetate coligands have been characterized by X-ray crystallography. IR and UV-Vis-spectroelectrochemistry reveals that oxidation of the heterobimetallic systems is highly localized at the organometallic manganese site, while electrochemical reduction occurs at cobalt. Structural and spectroscopic features as well as trends for the redox potentials of the $\mathrm{Mn}^{\mathrm{I}} / \mathrm{Mn}^{\mathrm{II}}$ couple suggest that changes at the cobalt(II) Werner-type subunit have only minor effects on the properties of the organometallic site.
\end{abstract}

Keywords: Bridging ligands; $N$-functionalized cyclopentadienyl ligands; Manganese; Cobalt; Bimetallic complexes

\section{Introduction}

The search for well-defined heterobimetallic complexes in recent years has been largely stimulated by the discovery of binuclear active sites in various metalloproteins. These metallobiosites are often highly unsymmetric. The metal centers reside in chemically different environments [1], have different accessibilities and assume quite distinct roles in the overall catalytic process. A prominent case is the respiratory protein hemerythrin that contains in its active site both a five-coordinate iron where the $\mathrm{O}_{2}$ substrate binds and an adjacent six-coordinate iron providing the second electron for dioxygen to hydroperoxide reduction [2]. Such intriguing metal ion cooperativity (sometimes referred to as one-site addition two-metal oxidation) has triggered the search for suitably designed

\footnotetext{
* Corresponding author. Tel.: +49 551 393012; fax: +49 551393063.

E-mail address: franc.meyer@chemie.uni-goettingen.de (F. Meyer).
}

unsymmetrical bimetallic complexes that could lead to similar reactivity patterns in a synthetic system [3]. Asymmetry in bridged binuclear metalloenzymes has provided lessons for the synthetic chemist also in a much broader sense, and a variety of unsymmetric compartmental ligand scaffolds

effects of the two metals $[1,4]$. One strategy to achieve coordination site distinction is the attachment of two different chelating side arms to an endogenenous bridging moiety such as phenolate [4,5], pyrazolate [6] or oxadiazole [7]. Few known systems, however, approach an extreme situation where both an organometallic and a Werner-type fragment with the same metal ion are preorganized in close proximity $[8,9]$.

In the case of pyrazolate-based homobimetallic complexes, the two metal ions spanned by the heterocycle are commonly in the same oxidation state $[10,11]$. It should be noted though that the pyrazolate bridge provides significant electronic coupling, and mutual metal oxidative deac- 
tivation upon oxidative addition to one of the two metals as well as fast electron transfer in mixed-valent species have been reported $[12,13]$. We have studied in detail a pyrazolate-bridged bimetallic system with two $\mathrm{CpMn}(\mathrm{CO})_{2}$ moieties appended to the 3- and 5-positions of the heterocycle. This dimanganese complex was shown to undergo two sequential one-electron metal-centered oxidations with fast intramolecular thermal electron transfer $\left(k_{\mathrm{ET}} \approx 2.6 \times\right.$ $10^{10} \mathrm{~s}^{-1}$ at $298 \mathrm{~K}$ ) in the mixed-valent $\mathrm{Mn}^{\mathrm{I}} \mathrm{Mn}^{\mathrm{II}}$ state having a formal low-spin $\mathrm{d}^{5} \mathrm{~d}^{6}$ electronic configuration [13]. In a further elaboration, the multifunctional type A system with both a $\mathrm{CpMn}(\mathrm{CO})_{2}$ subunit and a $\left\{\mathrm{N}_{4}\right\}$ ligand compartment tethered to the central pyrazole has been developed (Scheme 1). The $\left\{\mathrm{N}_{4}\right\}$ compartment is reminiscent of conventional mononucleating ligands of the tripodal tetradentate tris(pyridylalkyl)amine type. Manganese(II), nickel(II) or zinc(II) ions with different coligands $\mathrm{X}$ can be accommodated in the Werner-type compartment to give highly unsymmetric homo- or heterobimetallic systems B-D $[8,9,14]$, where variations in the Werner-type site were shown to induce only subtle changes of the redox properties of the organometallic site.

These highly unsymmetric binuclear compounds of generic type $\mathbf{E}$ can be formally described as a combination of each one type $\mathbf{F}$ and one type $\mathbf{G}$ subunit, i.e., as an assembly of both a Werner-type and an organometallic entity in a highly preorganized bimetallic array (Scheme 2). Two characteristics of type $\mathbf{E}$ complexes are noteworthy: firstly, the rigid chelate arrangement precludes dissociation of the organometallic fragment from the bridging pyrazolate, and secondly, the $\pi$ plane of the heterocycle roughly coincides with the mirror plane of the $\mathrm{Mn}(\mathrm{CO})_{2}$ moiety. The latter situation is most favorable for $\mathrm{Mn}$-pyrazolate $\pi$-interactions and hence for electronic communication between the $\mathrm{Mn}$ site and the second metal ion $[13,15,16]$.

In this work, we have now investigated a series of new heterobimetallic complexes similar to the type B-D systems, but with cobalt(II) in the classical (G-type) coordination site. With both metal ions being redox active $\left(\mathrm{Mn}^{\mathrm{l}} /\right.$ $\mathrm{Mn}^{\mathrm{II}}$ and $\left.\mathrm{Co}^{\mathrm{I}} / \mathrm{Co}^{\mathrm{II}} / \mathrm{Co}^{\mathrm{III}}\right)$, it appeared particularly interesting whether one-electron redox processes would be strictly confined to one site and whether any mutual influence of the adjacent metal ions might be discernible.

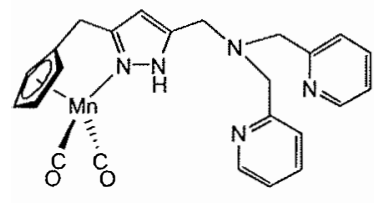

A

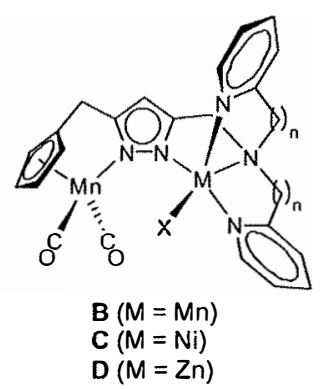

$D(M=Z n)$
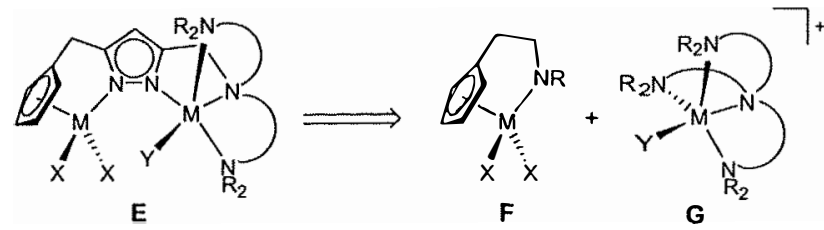

Scheme 2 .

\section{Results and discussion}

\subsection{Synthesis and structural characterization of complexes}

Cymantren derivatives 1 and $\mathbf{2}$ (Scheme 3) can be prepared in several steps from simple pyrazole derivatives, as reported previously [8]. They differ in the length of the pyridylalkyl side arms appended to the pyrazole heterocycle, thus constituting Werner-type $\left\{\mathrm{N}_{4}\right\}$ binding pockets with different chelate ring sizes. Photoinduced $\mathrm{CO}$ substitution leads to intramolecular coordination of the pyrazole- $\mathrm{N}$ to manganese, and a second metal ion may be accommodated in the $\left\{\mathrm{N}_{4}\right\}$ donor compartment upon subsequent deprotonation.

Heterobimetallic complexes with cobalt ions are best prepared in a one-pot procedure. Solutions of $\mathbf{1}$ or $\mathbf{2}$ are first irradiated with a high pressure mercury lamp in a quartz tube at $-40^{\circ} \mathrm{C}$ and are then treated with one equivalent of $\mathrm{KO} t \mathrm{Bu}$ and $\mathrm{Co}\left(\mathrm{NO}_{3}\right)_{2} \cdot 6 \mathrm{H}_{2} \mathrm{O}$ or $\mathrm{Co}(\mathrm{OA}$ c) $)_{2} \cdot 4 \mathrm{H}_{2} \mathrm{O}$, respectively. Single crystals of $3 \cdot \mathrm{Et}_{2} \mathrm{O}$, $4 \cdot 0.5 \mathrm{Et}_{2} \mathrm{O}$, and $5 \cdot 0.5 \mathrm{Et}_{2} \mathrm{O}$ could be obtained by slow diffusion of $\mathrm{Et}_{2} \mathrm{O}$ into DMF solutions of the products (Scheme 4). The ESI mass spectrum of $5\left(\mathrm{CH}_{2} \mathrm{Cl}_{2}\right.$ solution) shows dominant signals at $m / z=612$ for the anticipated ion and at $m / z=556$ for the complex devoid of two CO ligands. Details of the constitution of all three complexes have been elucidated by X-ray crystallography. Molecular structures are depicted in Figs. 1-3, together with selected atom distances and bond angles.

In all three complexes 3-5 the cobalt ion is nested in the classical $\left\{\mathrm{N}_{4}\right\}$ coordination site and the pyrazolate spans the two metal ions. The coordination environment for cobalt is completed either by a nitrate ( 3 and 4 ) or by an acetate anion (5). In the case of 4 and 5 these coligands are bound in a symmetric bidentate fashion with almost identical $\mathrm{Col}-\mathrm{O} 3$ and $\mathrm{Col}-\mathrm{O} 4$ bond lengths to give a

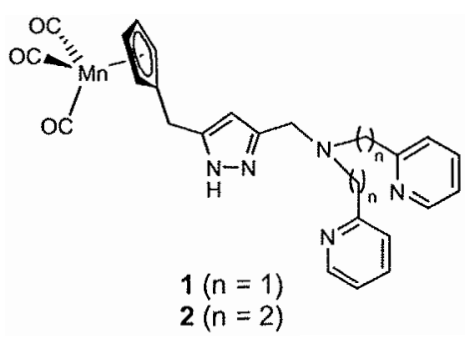

Scheme 3. 


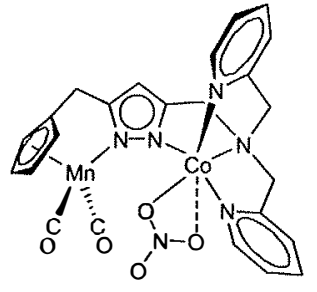

3

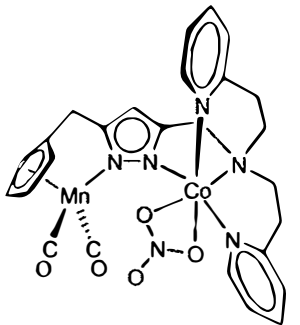

4

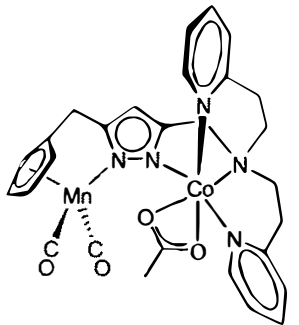

5

Scheme 4. Heterobimetallic Mn/Co complexes.

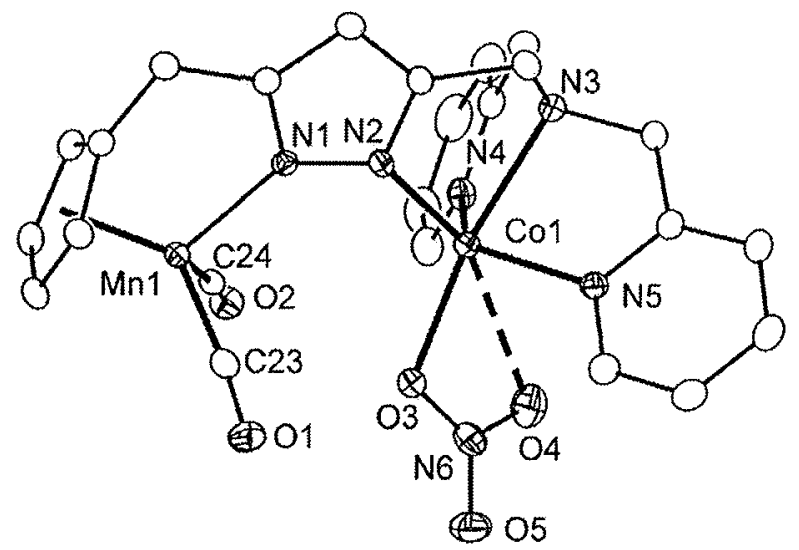

Fig. 1. ORTEP plot ( $30 \%$ probability thermal ellipsoids) of the molecular structure of 3 . For the sake of clarity all hydrogen atoms have been omitted. Selected atom distances $(\AA)$ and angles $\left({ }^{\circ}\right)(\mathrm{Cgl}$ defines the

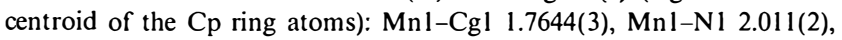

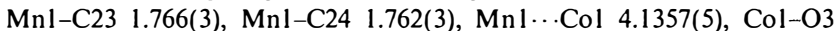
2.054(2), Col-O4 2.748(2), Col-N2 2.016(2), Col-N3 2.230(2), Col-N4 2.067(2), Col-N5 2.097(2), O1-C23 1.171(3), O2-C24 1.174(3); CglMnl-N1 112.1(1), Cgl-Mnl-C23 122.4(1), Cgl-Mnl-C24 125.0(1), C23-Mn(1)-C24 93.4(1), C23-Mnl-N1 99.5(1), C24-Mnl-N1 99.5(1), O1-C23-Mnl 172.8(2), O2-C24-Mnl 174.0(2), N2-Col-N3 78.4(1), N2Col-N4 109.7(1), N2-Col-N5 111.5(1), N2-Col-O3 107.2(1), N2-ColO4 157.9(1), N3-Col-N4 77.9(1), N3-Col-N5 76.1(1), N3-Col-O3 169.0(1), N3-Col-O4 123.7(1), N4-Col-N5 124.8(1), N4-Col-O3 108.3(1), N4-Col-O4 79.7(1), N5-Col-O3 92.9(1), N5-Col-O4 75.8(1).

severely distorted octahedral environment for the metal ion, while the nitrate in $\mathbf{3}$ is semi-bidentate with a significantly longer Col-O4 distance of $2.75 \AA$ compared to the short Col-O3 bond of $2.05 \AA$. The situation for 3 is thus better described as $\{5+1\}$ coordination. It should be noted that the $\left\{\mathrm{N}_{4}\right\}$ compartment of $\mathbf{1}$ (and $\mathbf{3}$ ) is closely related to the well-known tripodal tetradentate TPA (TPA $=\operatorname{tris}(2-$ pyridylmethyl)amine), which often favors a trigonal-bipyramidal metal coordination in its $3 \mathrm{~d}$ transition metal complexes. As a consequence, the mononuclear complex $\left[\mathrm{Co}^{\mathrm{II}}(\mathrm{TPA})(\mathrm{OAc})\right]^{+}(\mathbf{H}$; Scheme 5) shows semi-bidentate acetate binding with markedly different

[17]. The Mn -..Co separation in 3-5 strongly depends on the length of the ligand side arms of the $\left\{\mathrm{N}_{4}\right\}$ compartment. With longer chelate arms (4 and 5) a Mn...Co distance of $4.41-4.45 \AA$ is observed whereas the shorter side arms in 3 compress the Mn...Co distance to $4.14 \AA$. A sim-

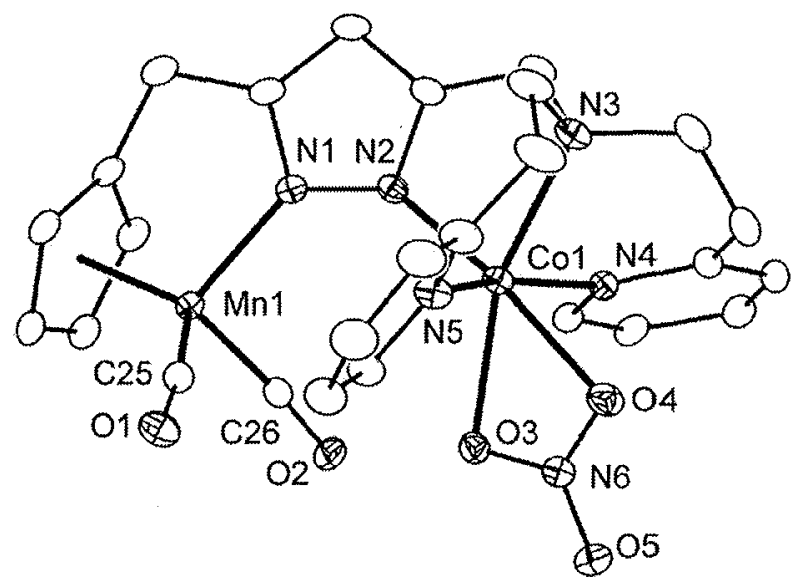

Fig. 2. ORTEP plot (30\% probability thermal el lipsoids) of the molecular structure of 4 . For the sake of clarity all hydrogen atoms have been omitted. Selected atom distances $(\AA)$ and angles $\left({ }^{\circ}\right)(\mathrm{Cgl}$ defines the centroid of the $\mathrm{Cp}$ ring atoms): Mnl-Cgl 1.7718(9), Mnl-N1 2.048(2),

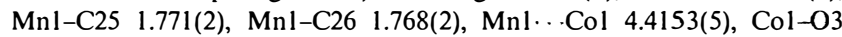
2.229(1), Col-O4 2.211(1), Col-N2 2.056(2), Col-N3 2.178(2), Col-N4 2.136(2), Col-N5 2.126(2), O1-C25 1.172(2), O2-C26 1.171(2); CglMnl-N1 112.1(1), Cgl-Mnl-C25 121.7(1), Cgl-Mnl-C26 123.1(1), C25-Mn(1)-C26 93.6(1), C25-Mnl-N1 103.9(1), C26-Mnl-N1 98.7(1), O1-C25-Mnl 171.3(2), O2-C26-Mnl 173.9(2), N2-Col-N3 82.7(1), N2Col-N4 94.7(1), N2-Col-N5 101.7(1), N2-Col-O3 112.8(1), N2-ColO4 170.6(1), N3-Col-N4 83.7(1), N3-Col-N5 94.3(1), N3-Col-O3 161.9(1), N3-Col-O4 105.7(1), N4-Col-N5 163.1(1), N4-Col-O3 85.8(1), N4-Col-O4 82.1(1), N5-Col-O3 91.6(1), N5-Col-O4 82.3(1).

ilar difference of approximately $0.3 \AA$ was also reported for related $\mathrm{Mn}-\mathrm{Zn}$ complexes with the same pyrazole-based ligands and similar arrangement of the metal ions [8]. In the related zinc acetate complex derived from 1 , one of the acetato-O atoms is displaced completely out of the coordination sphere of the metal atom. It is unclear at present whether the sterically less demanding semi-bidentate or monodentate co-ligand binding in complexes of 1 allows the two metal ions to approach more closely, or whether the different $\mathrm{Mn}$...Co separations are largely a result of the constraints imposed by the pyrazolate-based ligand scaffold. This may then lead to a particularly pronounced asymmetry in co-ligand binding due to crowding within the bimetallic pocket. The observation of an almost symmetric co-ligand binding in a related manganese acetate complex derived from 1 [9] argues against the latter explanation and suggests a rather flexible arrangement that is 


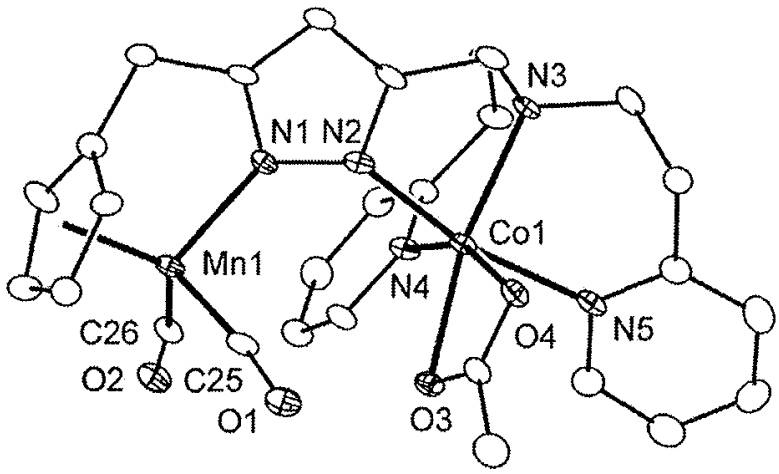

Fig. 3. ORTEP plot (30\% probability thermal el lipsoids) of the molecular structure of 5 . For the sake of clarity all hydrogen atoms have been omitted. Selected atom distances $(\AA)$ and angles $\left({ }^{\circ}\right)(\mathrm{Cg}(1)$ defines the centroid of the $\mathrm{Cp}$ ring atoms): $\mathrm{Mnl}-\mathrm{Cg} 1$ 1.768(4), Mnl-N1 2.038(5),

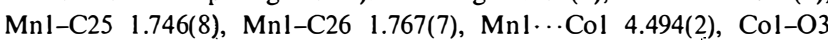
2.162(5), Col-O4 2.163(5), Col-N2 2.104(6), Col-N3 2.186(5), Col-N4 2.115(5), Col-N5 2.181(6), O1-C25 1.202(8), O2-C26 1.177(8); Cg1$\mathrm{Mnl-N1}$ 112.5(2), Cgl-Mnl-C25 122.2(3), Cgl-Mnl-C26 121.4(3), C25-Mn(1)-C26 93.8(3), C25-Mnl-N1 98.9(3), C26-Mnl-N1 104.1(3), O1-C25-Mnl 172.2(6), O2-C26-Mnl 169.5(6), N2-Col-N3 81.6(2), N2-Col-N4 97.7(2), N2-Col-N5 166.8(2), N2-Col-O3 103.9(2), N2Col-O4 92.9(2), N3-Col-N4 93.9(2), N3-Col-N5 87.2(2), N3-Col-O3 165.5(2), N3-Col-O4 105.8(2), N4-Col-N5 89.9(2), N4-Col-O3 98.6(2), N4-Col-O4 158.8(2), N5-Col-O3 85.5(2), N5-Col-O4 83.4(2).

also effected by the individual stereoelectronic requirements of the metal ion.

Comparison of the $\mathrm{Mn}-\mathrm{Cg}(\mathrm{Cg}$ defines the centroid of the ring atoms of the cyclopentadienylanion), $\mathrm{Mn}-\mathrm{CO}$, $\mathrm{Mn}-\mathrm{N}$, and $\mathrm{C} \equiv \mathrm{O}$ bond lengths of $\mathbf{3 , 4}$ and 5 or related $\mathrm{Mn} / \mathrm{Zn}, \mathrm{Mn} / \mathrm{Ni}$, and $\mathrm{Mn} / \mathrm{Mn}$ complexes as well as mono-

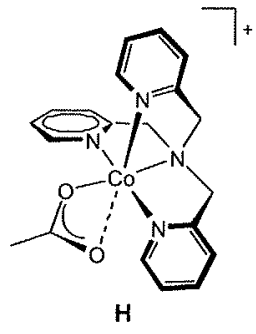

Scheme 5 nuclear Mn complexes derived from 1 and 2 where only the organometallic binding site is occupied reveals that the metal ion in the classical Werner-type site has only little influence on the bonding parameters of the organometallic $\mathrm{CpMn}(\mathrm{CO})_{2}$ fragment (Table 1). Also the bond angles of the $\mathrm{CpMn}(\mathrm{CO})_{2}$ moiety are very similar throughout the series of complexes, with the exception of the OC-Mn-N angle that spans a range from $94.8^{\circ}$ to $104.1^{\circ}$ (Table 1). This particular angle seems to be sensitive to changes in the coordination sphere of the metal nested within the classical Werner-type site, rather because of steric than of electronic effects.

\subsection{Spectroscopic and electrochemical trends}

Each complex 3-5 shows two strong IR bands of similar relative intensities in the $\mathrm{C} \equiv \mathrm{O}$ stretching region, with $v_{\mathrm{as}}(\mathrm{CO})$ and $v_{\mathrm{s}}(\mathrm{CO})$ of the $\left\{\mathrm{Mn}(\mathrm{CO})_{2}\right\}$ fragment at around 1900 and $1832 \mathrm{~cm}^{-1}$, respectively (Table 2 ). There is no notable effect

compartment ( 3 vs. 4 ), or of the co-ligand at cobalt ( 4 vs. 5). Complex 5 features strong bands at 1566 and $1436 \mathrm{~cm}^{-1}$ that are assigned to the acetate ligand. The small difference

dance with bidentate acetate coordination [18].

Cyclic voltammograms of complexes 3-5 in acetonitrile/ $\mathrm{NBu}_{4} \mathrm{ClO}_{4}$ solution feature a reversible redox wave in the range $E_{1 / 2}=-0.44$ to $-0.61 \mathrm{~V}$ (Table 3) [19], which we assign to the formation of the $\mathrm{Mn}^{\mathrm{II}} \mathrm{Co}^{\mathrm{II}}$ species. The cyclic voltammogram of 4 is depicted in Fig. 4 as an example. Oxidation potentials of $\mathrm{CpMn}(\mathrm{CO})_{2} \mathrm{~L}$ complexes are known to vary over a potential range of more than $2 \mathrm{~V}$, depending of the nature of the ligand $\mathrm{L}[15,16,20]$. The rather low oxidation potentials of 3-5 indicate significant stabilization of the $\mathrm{Mn}^{\text {II }}$ state by the anionic pyrazolate ligand and reflect the high nucleophilicity of the N-heterocycle in these heterobimetallic species [20]. Small influences of the ligand chelate ring size or the co-ligand at cobalt on the $\mathrm{Mn}^{\mathrm{I}} / \mathrm{Mn}^{\mathrm{II}}$ redox potential are discernible, revealing a certain degree of electronic communication between the proximate metal ions. The more strongly coordinating (and more electron donating) acetate at cobalt renders oxidation of the organometallic site more easy by $60 \mathrm{mV}$ as

Table 1

Comparison of selected bond distances $(\AA)$ and angles $\left(^{\circ}\right)$

\begin{tabular}{lcccc}
\hline & Mn only $(\mathbf{A})^{8 b}$ & $\mathrm{Mn} / \mathrm{Mn}(\mathrm{B})^{9}$ & $\mathrm{Mn} / \mathrm{Ni}(\mathrm{C})^{14}$ & $\mathrm{Mn} / \mathrm{Zn}(\mathbf{D})^{8}$ \\
\hline $\mathrm{Mn}-\mathrm{Cg}$ & 1.77 & $1.76-1.77$ & 1.77 & 1.77 \\
$\mathrm{Mn}-\mathrm{N}$ & $2.01-2.02$ & $2.01-2.03$ & $2.02-2.05$ & $1.99-2.03$ \\
$\mathrm{Mn}-\mathrm{CO}$ & $1.77-1.78$ & $1.76-1.78$ & $1.75-1.77$ & $1.76-1.77$ \\
$\mathrm{C} \equiv \mathrm{O}$ & $1.16-1.17$ & $1.16-1.17$ & $1.17-1.18$ & $1.76-1.77$ \\
$\mathrm{Cg}-\mathrm{Mn}-\mathrm{N}$ & 111.2 & $11.6-112.7$ & $1.16-1.19$ \\
$\mathrm{Cg}-\mathrm{Mn}-\mathrm{CO}$ & $123.9-127.2$ & $121.2-126.0$ & $111.9-112.8$ & $110.8-112.5$ \\
$\mathrm{CO}-\mathrm{Mn}-\mathrm{CO}$ & $89.4-91.4$ & $91.4-92.8$ & $123.7-124.0$ & $122.4-128.3$ \\
$\mathrm{CO}-\mathrm{Mn}-\mathrm{N}$ & $96.0-102.2$ & $94.8-102.7$ & $90.3-91.8$ & $112.1-112.5$ \\
\hline
\end{tabular}

Apart from the long $\mathrm{Co}-\mathrm{O}$ bond in 3 all $\mathrm{Co}-\mathrm{O} / \mathrm{N}$ bond lengths lie within the range usually reported for octahedral cobalt(II) complexes with a comparable $\mathrm{N}_{4} \mathrm{O}_{2}(-\mathrm{NO})$ or $\mathrm{N}_{4} \mathrm{O}_{2}\left(-\mathrm{CCH}_{3}\right)$ coordination sphere $\left(\mathrm{Co}-\mathrm{ONO}_{2}\right.$ : 1.9-2.3 $\mathrm{A}$, Co-OAc: $2.1-2.3 \AA$, Co-N: 1.9-2.3 $\mathrm{A}$; data from CSD). 
Table 2

IR absorptions in the $\mathrm{CO}$ stretching range; values in $\mathrm{cm}^{-1}$

\begin{tabular}{lll}
\hline & Solution $^{\text {a }}$ & $\mathrm{KBr}$ pellets \\
\hline $\mathbf{3}$ & 1907,1830 & 1906,1821 \\
$\mathbf{3}^{+}$ & 2037,1958 & \\
$\mathbf{4}$ & 1906,1828 & 1905,1822 \\
$\mathbf{4}^{+\mathbf{r}}$ & 2030,1952 & \\
$\mathbf{5}$ & 1906,1828 & 1898,1822 \\
$\mathbf{5}^{+}$ & 2029,1951 & \\
\hline
\end{tabular}

${ }^{a} \mathrm{MeCN}$ for 3, dichloroethane for $\mathbf{4}$ and $\mathbf{5}$.

Table 3

Formal potentials for the $\mathrm{Mn}^{\mathrm{I}} / \mathrm{Mn}^{\mathrm{II}}$ couple in $\mathrm{MeCN} / 0.1 \mathrm{M} \mathrm{NBu} \mathrm{ClO}_{4}$ [19]

\begin{tabular}{lll}
\hline Complex & $E_{1 / 2}\left(\mathrm{Mn}^{\mathrm{I}} \mathrm{Co}^{\mathrm{II}} / \mathrm{Mn}^{\mathrm{II}} \mathrm{Co}^{\mathrm{II}}\right)$ & $E_{1 / 2}^{\mathrm{red}}\left(\mathrm{Mn}^{\mathrm{I}} \mathrm{Co}^{\mathrm{II}} / \mathrm{Mn}^{\mathrm{I}} \mathrm{Co}^{\mathrm{I}}\right)$ \\
\hline $\mathbf{3}$ & -0.44 & $-1.82^{\mathrm{a}}$ \\
$\mathbf{4}$ & -0.55 & -1.65 \\
$\mathbf{5}$ & -0.61 & $-2.56^{\mathrm{b}}$ \\
\hline a & \\
${ }^{\mathrm{b}}$ Only partially reversible. &
\end{tabular}

compared to the corresponding nitrate complex (5 vs. 4 ). The oxidation wave of the nitrate complex with shorter chelate arms at cobalt (3) is shifted anodically by $110 \mathrm{mV}$ with respect to the congeners with longer chelate arms. In comparison to the analogous $\mathrm{Mn} / \mathrm{Zn}$ complexes, changes at the $\left\{\mathrm{N}_{4}\right\}$ coordination sphere of the cobalt(II) ion in 3 and 4 exert a slightly more pronounced influence on the manganese redox potential. Only complexes 3 and 4 show a partially or quasi-reversible reduction at -1.82 or $-1.65 \mathrm{~V}$, while for the acetate complex 5 reduction is an irreversible process and occurs at much lower potential around $-2.5 \mathrm{~V}$ vs. ferrocene. The strong effect of the co-

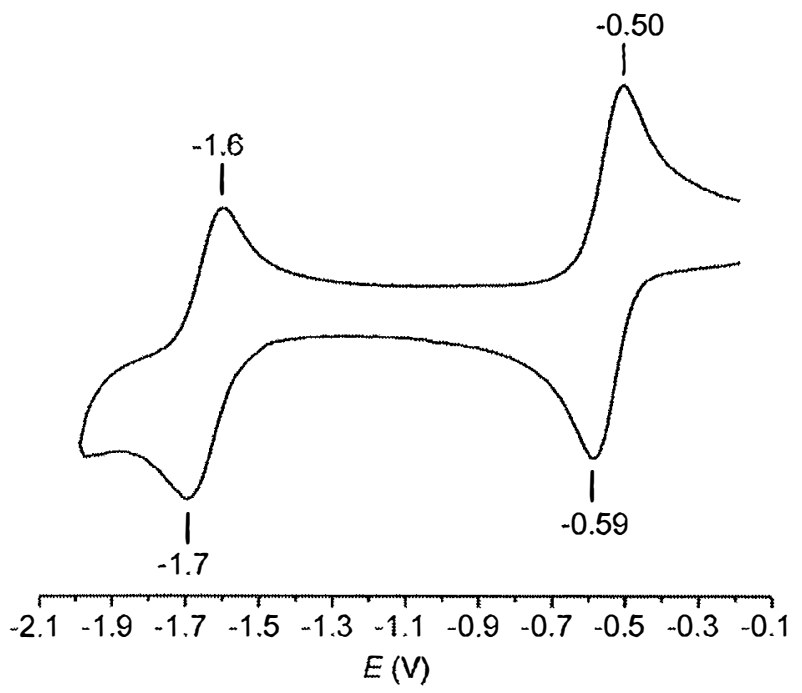

Fig. 4. Cyclic voltammogram of 4 recorded on a platinum electrode in acetonitrile containing $\sim 0.1 \mathrm{M} \mathrm{NBu}_{4} \mathrm{ClO}_{4}$; scan speed $100 \mathrm{mV} \mathrm{s}^{-1}$; potentials are given in volts vs. the $\mathrm{Fc} / \mathrm{Fc}^{+}$couple. ligand (acetate or nitrate) supports the idea that reduction is mainly localized at cobalt $\left(\mathrm{Co}^{\mathrm{II}} / \mathrm{Co}^{\mathrm{I}}\right)$.

To unambiguously establish the site of oxidation and to further characterize the resulting species, oxidation of 3-5 in $\mathrm{MeCN} / \mathrm{NBu}_{4} \mathrm{PF}_{6}$ (3) or $1,2-\mathrm{C}_{2} \mathrm{H}_{4} \mathrm{Cl}_{2} / \mathrm{NBu}_{4} \mathrm{PF}_{6}$ (4 and 5) was followed by IR and UV-Vis spectroscopy in an OTTLE cell (Figs. 5-7, S1, S2). Upon gradual electrolysis the pair of $\mathrm{CO}$ stretching vibrations at around 1830 and $1906 \mathrm{~cm}^{-1}$ decreases at the expense of two new bands at around 1955 and $2030 \mathrm{~cm}^{-1}$, thus confirming structural integrity of the $\mathrm{CpMn}(\mathrm{CO})_{2}$ fragment upon generation of the oxidized species $3^{+}-5^{+}$. The slightly lower intensity of the new bands is as expected, since in $\mathrm{M}-\mathrm{CO}$ moieties spec-

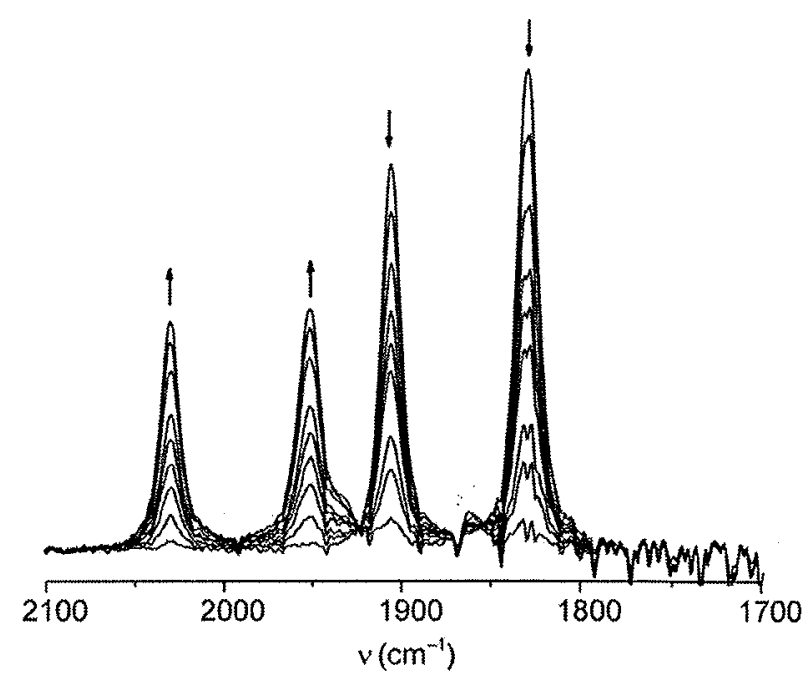

Fig. 5. IR spectroscopic changes during gradual oxidation $4 \rightarrow \mathbf{4}^{+}$in $\mathrm{DCE} / \mathrm{NBu}_{4} \mathrm{PF}_{6}$ solution in an OTTLE cell.

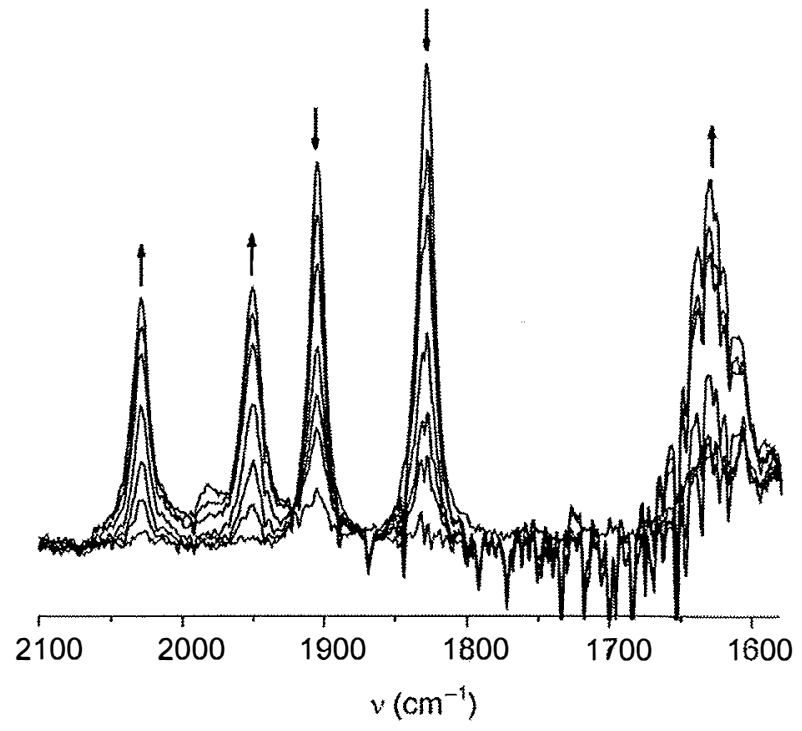

Fig. 6. IR spectroscopic changes during gradual oxidation $5 \rightarrow 5^{+}$in $\mathrm{DCE} / \mathrm{NBu}_{4} \mathrm{PF}_{6}$ solution in an OTTLE cell. 


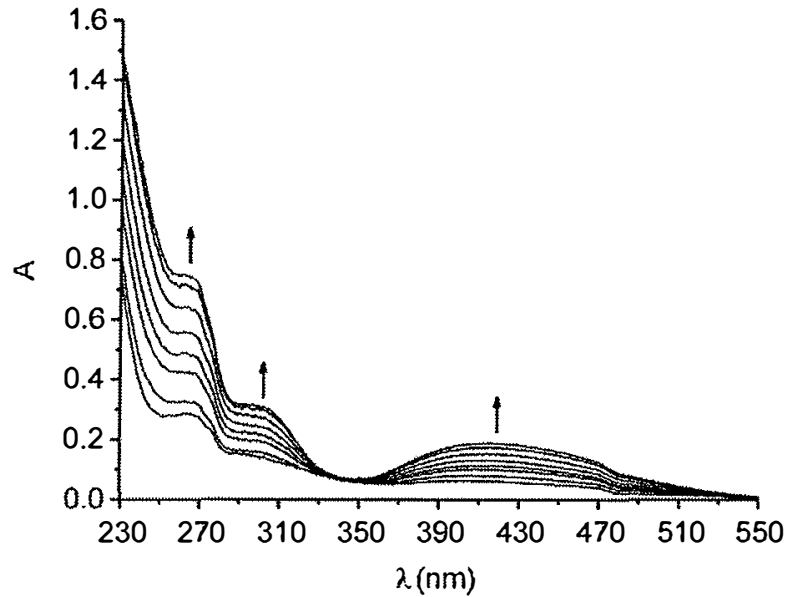

Fig. 7. UV-Vis spectroscopic changes during gradual oxidation $4 \rightarrow \mathbf{4}^{+}$in $\mathrm{DCE} / \mathrm{NBu}_{4} \mathrm{PF}_{6}$ solution in an OTTLE cell.

tral intensities usually decrease with increasing oxidation state [21]. The shift to higher energies of $\sim 120 \mathrm{~cm}^{-1}$ is very similar to the ones observed in the corresponding $\mathrm{Mn} / \mathrm{Zn}$ and $\mathrm{Mn} / \mathrm{Mn}$ complexes and reflects the diminished backbonding ability in the oxidized $\mathrm{CpMn}^{\mathrm{II}}(\mathrm{CO})_{2}$ subunit. This clearly reveals that the anodic process in the present $\mathrm{Mn} /$ Co systems is centered at the organometallic site, i.e., cobalt remains in the +II oxidation state. The presence of several isosbestic points confirms clean conversion between the $\mathrm{Mn}^{\mathrm{I}} \mathrm{Co}^{\mathrm{II}}$ and $\mathrm{Mn}^{\mathrm{II}} \mathrm{Co}^{\mathrm{II}}$ species. In the case of 4 and 5 the original spectra of the starting materials are not fully restored upon re-reduction. Intensities of the CO stretching vibrations only reach around $60 \%$ of their original values, suggesting that the oxidized complexes of the systems derived from $\mathbf{2}$ have limited stability in solution. Accordingly, attempts to crystallize any of the $\mathrm{Mn}^{\mathrm{II}} \mathrm{Co}^{\mathrm{II}}$ complexes after chemical oxidation have hitherto failed. Upon in situ oxidation of 5, a new intense IR band at $1630 \mathrm{~cm}^{-1}$ appears (Fig. 6) that is tentatively assigned to a carboxylate vibration of the acetate, suggesting major changes in the acetate coordination mode. This latter band does not vanish upon re-reduction, which confirms that the oxidized species gradually undergoes some structural transformation.

In UV-Vis spectroelectrochemistry, the oxidation of 3-5 is accompanied by an increase in absorptivity in the UV range and by the appearance of a new band at around $410 \mathrm{~nm}$ (Figs. 7 and S2). The rise of a similar band at $\sim 400 \mathrm{~nm}$ has also been observed upon oxidation of the corresponding $\mathrm{Mn} / \mathrm{Zn}$ and $\mathrm{Mn} / \mathrm{Mn}$ systems and can thus be safely assigned to the $\pi$ (pyrazolate) $\rightarrow \mathrm{CpMn}^{\mathrm{II}}(\mathrm{CO})_{2}$ LMCT transition, which obviously is relatively insensitive to the identity of the metal ion within the adjacent Werner-type $\left\{\mathrm{N}_{4}\right\}$ compartment.

Electrochemical reduction of 3 in $\mathrm{MeCN} / \mathrm{NBu}_{4} \mathrm{PF}_{6}$ reveals only minor IR spectroscopic changes for the $\mathrm{CO}$ stretching vibrations (Fig. 8), which confirms that reduction is localized at cobalt and does hardly affect the orga-

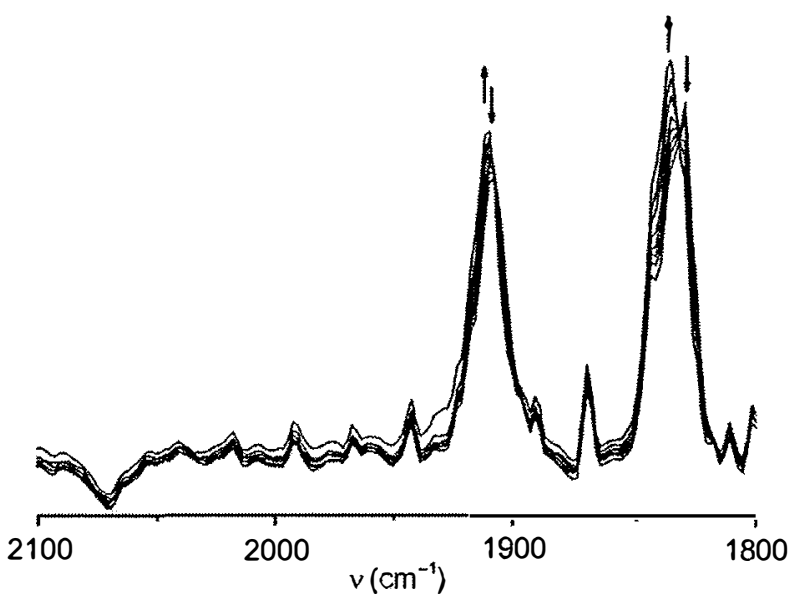

Fig. 8. IR spectroscopic changes during gradual reduction $3 \rightarrow 3^{-}$in $\mathrm{MeCN} / \mathrm{NBu}_{4} \mathrm{PF}_{6}$ solution in an OTTLE cell.

nometallic $\mathrm{CpMn}(\mathrm{CO})_{2}$ subunit [22]. Their instability precludes isolation of the reduced species.

\section{Conclusions}

A set of highly unsymmetric heterodinuclear $\mathrm{Mn} / \mathrm{Co}$ type A complexes based on a bridging pyrazolate has been prepared, and three complexes have been structurally characterized. They differ by the chelate ring size of the Werner-type $\left\{\mathrm{N}_{4}\right\}$ compartment or the co-ligand at cobalt (nitrate or acetate). Structural characteristics of the two individual subunits are reminiscent of their corresponding mononuclear analogues, which supports a description of the present bimetallic systems as hybrids of an organometallic $\mathrm{CpMn}(\mathrm{CO})_{2}$ fragment and a classical Werner-type tris(pyridylalkyl)amine cobalt(II) complex. Oxidation occurs at rather low potentials and, according to IR spectroelectrochemistry, is highly localized at the organometallic manganese site. Slight effects of the Werner-type cobalt(II) subunit on the $\mathrm{Mn}^{\mathrm{I}} / \mathrm{Mn}^{\mathrm{II}}$ redox potentials are discernible, while variations of the co-ligand at cobalt or the $\left\{\mathrm{N}_{4}\right\}$ chelate ring size have hardly any effect on the spectroscopic signatures of the proximate organometallic site. In contrast, reduction appears to occur at the cobalt ion and leads to only minor changes at the $\mathrm{CpMn}(\mathrm{CO})_{2}$ subunit. Future work will aim at modifying the classical ligand compartment in such a way that the $\mathrm{Co}^{\mathrm{II}} / \mathrm{Co}^{\mathrm{III}}$ potential is in the same range as the $\mathrm{Mn}^{\mathrm{I}} / \mathrm{Mn}^{\mathrm{II}}$ potential, and at exploring the potential of these systems for bimetallic redox reactivity of the "one-site addition two-metal oxidation" type.

\section{Experimental}

General procedures and methods. Manipulations were carried out under an atmosphere of dry nitrogen by employing standard Schlenk techniques. 3-bis(pyridylmethyl)amino5-tricarbonylcyclopentadienylmanganese- $1 \mathrm{H}$-pyrazole 
and 3-bis(pyridylethyl)amino-5-tricarbonylcyclopentadienylmanganese- $1 H$-pyrazole (2) were prepared as reported previously [8]. Solvents were dried according to established procedures. All other chemicals were obtained from commercial sources and used as received. IR spectra were recorded as $\mathrm{KBr}$ pellets with a Digilab Excalibur. ESI mass spectra were measured with a Finnigan MAT LCQ. Elemental analyses were performed by the analytical laboratory of the Institut für Anorganische Chemie der Universität Göttingen using a Heraeus CHN-O-RAPID instrument. Cyclic voltammetry was carried out with a pontiostat/galvanostat Perkin-Elmer Model 263A instrument with glassy carbon working electrode and platinum reference and counter electrodes, in $0.1 \mathrm{M} \mathrm{NBu}_{4} \mathrm{ClO}_{4} / \mathrm{CH}_{3} \mathrm{CN}$; ferrocene (the potential in $\mathrm{MeCN}$ being $0.38 \mathrm{~V}$ against SCE) [23] was used as internal standard. Spectroelectrochemistry was performed with a self-constructed OTTLE cell comprising a Pt-mesh working and counter electrode and a silver wire as pseudeo-reference electrode sandwiched in between the $\mathrm{CaF}_{2}$ windows of a conventional liquid IR cell. The working electrode is positioned in the center of the spectrometer beam with all other parts of the cell made non-transparent to the incident beam by means of an absorbing tape [24].

\subsection{Complex 3}

A solution of $1(0.206 \mathrm{~g}, 0.42 \mathrm{mmol})$ in THF $(200 \mathrm{ml})$ was irradiated with high pressure mercury lamp in a quartz tube at $-40^{\circ} \mathrm{C}$. Within about $1 \mathrm{~h}$ the color of the solution gradually changed from light yellow to yellow, and the solution was then allowed to warm to room temperature. $\mathrm{KO}^{\prime} \mathrm{Bu} \quad(0.047 \mathrm{~g}, \quad 0.42 \mathrm{mmol})$ and $\mathrm{Co}\left(\mathrm{NO}_{3}\right)_{2} \cdot 6 \mathrm{H}_{2} \mathrm{O}$ $(0.122 \mathrm{~g}, 0.42 \mathrm{mmol})$ were added. The reaction mixture was stirred overnight, producing a yellow precipitate which was filtered, washed with petroleum ether, and dried under reduced pressure. Crystals of $\mathbf{3} \cdot \mathrm{Et}_{2} \mathrm{O}$ were obtained after several days by slow diffusion of diethyl ether into a concentrated DMF solution of the crude product. The crystals were separated by filtration, washed with diethyl ether, and dried under reduced pressure. Yield: $37 \mathrm{mg}$ (13\%). IR $(\mathrm{KBr})\left(\mathrm{cm}^{-1}\right): 2971 \mathrm{w}, 2895 \mathrm{w}, 1906 \mathrm{vs}, 1821 \mathrm{vs}, 1654 \mathrm{~m}$, $1609 \mathrm{~m}, 1570 \mathrm{w}, 1473 \mathrm{~m}, 1442 \mathrm{~m}, 1380 \mathrm{~s}, 1296 \mathrm{~m}, 1155$ w, 1104 w, 1057 w, 1022 w, 970 w, 893 w, 829 w, 771 m, $655 \mathrm{w}, 610 \mathrm{w}, 589 \mathrm{w}, 510 \mathrm{w}, 480 \mathrm{w}, 419 \mathrm{w}$. The dried compound has lost the solvent of crystallisation but appears to be hygroscopic. Anal. Calc. for $\mathrm{C}_{24} \mathrm{H}_{21} \mathrm{CoMnN}_{6} \mathrm{O}_{5} \cdot 2 \mathrm{H}_{2} \mathrm{O}$ (587.34): C, 46.24; H, 4.04; N, 13.48. Found: C, 45.68; H, $4.10 ; \mathrm{N}, 13.50 \%$.

\subsection{Complex 4}

A solution of $2(0.206 \mathrm{~g}, 0.39 \mathrm{mmol})$ in THF $(200 \mathrm{ml})$ was irradiated with high pressure mercury lamp in a quartz tube at $-40^{\circ} \mathrm{C}$. Within about $1 \mathrm{~h}$ the color of the solution gradually changed from light yellow to yellow, and the solution was then allowed to warm to room temperature.
$\mathrm{KO} t \mathrm{Bu} \quad(0.044 \mathrm{~g}, \quad 0.39 \mathrm{mmol})$ and $\mathrm{Co}\left(\mathrm{NO}_{3}\right)_{2} \cdot 6 \mathrm{H}_{2} \mathrm{O}$ $(0.114 \mathrm{~g}, 0.39 \mathrm{mmol})$ were added. The reaction mixture was stirred overnight, producing a yellow precipitate which was filtered, washed with petroleum ether, and dried under reduced pressure. Crystals of $4 \cdot 0.5 \mathrm{Et}_{2} \mathrm{O}$ were obtained after several days by slow diffusion of diethyl ether into a concentrated DMF solution of the crude product. The crystals were separated by filtration, washed with diethyl ether, and dried under reduced pressure. Yield: $38 \mathrm{mg} \mathrm{(15 \% ).} \mathrm{IR}$ $(\mathrm{KBr})\left(\mathrm{cm}^{-1}\right): 2964 \mathrm{w}, 2912 \mathrm{w}, 2860 \mathrm{w}, 1905 \mathrm{vs}, 1822 \mathrm{vs}$, $1665 \mathrm{~m}, 1604 \mathrm{~m}, 1569 \mathrm{w}, 1481 \mathrm{~s}, 1445 \mathrm{~m}, 1386 \mathrm{~m}, 1341 \mathrm{~m}$, $1280 \mathrm{~m}, 1153 \mathrm{w}, 1103 \mathrm{~m}, 1054 \mathrm{w}, 1017 \mathrm{~m}, 951 \mathrm{w}, 897 \mathrm{w}$, $815 \mathrm{w}, 765 \mathrm{~m}, 653 \mathrm{w}, 607 \mathrm{w}, 527 \mathrm{w}, 473 \mathrm{w}, 419 \mathrm{w}$. The dried compound has lost the solvent of crystallisation. Anal. Calc. for $\mathrm{C}_{26} \mathrm{H}_{25} \mathrm{CoMnN}_{6} \mathrm{O}_{5}$ (615.39): C, 50.75; H, 4.09; N, 13.66. Found: C, 50.15; H, 4.37; N 13.61\%.

\subsection{Complex 5}

A solution of $2(0.206 \mathrm{~g}, 0.39 \mathrm{mmol})$ in THF $(200 \mathrm{ml})$ was irradiated with high pressure mercury lamp in a quartz tube at $-40^{\circ} \mathrm{C}$. Within about $1 \mathrm{~h}$ the color of the solution gradually changed from light yellow to yellow, and the solution was then allowed to warm to room temperature. $\mathrm{KO} t \mathrm{Bu}(0.044 \mathrm{~g}, 0.39 \mathrm{mmol})$ and $\mathrm{Co}\left(\mathrm{CH}_{3}\right.$ $\mathrm{COO})_{2} \cdot 4 \mathrm{H}_{2} \mathrm{O}(0.097 \mathrm{~g}, 0.39 \mathrm{mmol})$ were added. The reaction mixture was stirred overnight, producing a yellow precipitate which was filtered, washed with petroleum ether, and dried under reduced pressure. Crystals of $5 \cdot 0.5 \mathrm{Et}_{2} \mathrm{O}$ were obtained after several days by slow diffusion of diethyl ether into a concentrated DMF solution of the crude product. The crystals were separated by filtration, washed with diethyl ether, and dried under reduced pressure. Yield: $67 \mathrm{mg}(28 \%)$. IR (KBr) $\left(\mathrm{cm}^{-1}\right)$ : $2967 \mathrm{w}$, $2911 \mathrm{w}, 2858 \mathrm{w}, 1898 \mathrm{vs}, 1822 \mathrm{vs}, 1666 \mathrm{w}, 1566 \mathrm{~m}$, $1481 \mathrm{~m}, 1436 \mathrm{~s}, 1339 \mathrm{~m}, 1308 \mathrm{~m}, 1150 \mathrm{w}, 1108 \mathrm{w}, 1050$ m, $1016 \mathrm{~m}, 946 \mathrm{w}, 900 \mathrm{w}, 817 \mathrm{w}, 763 \mathrm{~m}, 662 \mathrm{w}, 609 \mathrm{w}$, $591 \mathrm{w}, 527 \mathrm{w}, 478 \mathrm{w}, 421 \mathrm{w}$. ESI-MS $\left(\mathrm{CH}_{2} \mathrm{Cl}_{2}\right): \mathrm{m} / \bar{z}$ $(\%)=612\left(92, \mathrm{M}^{+}\right), 556\left(100,[\mathrm{M}-2 \mathrm{CO}]^{+}\right)$. The dried compound has lost the solvent of crystallisation but appears to be hygroscopic. Anal. Calc. for $\mathrm{C}_{28} \mathrm{H}_{28} \mathrm{CoMn}$ $\mathrm{N}_{5} \mathrm{O}_{4} \cdot \mathrm{H}_{2} \mathrm{O}$ (630.45): C, 53.34; H, 4.80; N, 11.11. Found: C, 52.97; H, 4.68; N, 10.63\%.

\subsection{X-ray crystallography of complexes 3-5}

X-ray data were collected on a STOE IPDS II diffractometer (graphite monochromated Mo $\mathrm{K} \alpha$ radiation, $\lambda=0.71073 \AA$ ) by use of $\omega$ scans at $-140^{\circ} \mathrm{C}$ (Table 4 ). The structures were solved by direct methods and refined on $F^{2}$ using all reflections with sHELX-97 [25]. The nonhydrogen atoms were refined anisotropically. Hydrogen atoms were placed in calculated positions and assigned to an isotropic displacement parameter of $0.08 \AA^{2}$. Faceindexed absorption corrections were performed numerically with the program X-RED [26]. The geometrical aspects of the structures were analyzed by using the PLATON 
Table 4

Crystal data and refinement details for 3,4 and 5

\begin{tabular}{|c|c|c|c|}
\hline & $3 \cdot \mathrm{Et}_{2} \mathrm{O}$ & $4 \cdot 0.5 \mathrm{Et}_{2} \mathrm{O}$ & $5 \cdot 0.5 \mathrm{Et}_{2} \mathrm{O}$ \\
\hline Formula & $\mathrm{C}_{24} \mathrm{H}_{21} \mathrm{CoMnN}_{6} \mathrm{O}_{5}, \mathrm{C}_{4} \mathrm{H}_{10} \mathrm{O}$ & $\mathrm{C}_{26} \mathrm{H}_{25} \mathrm{CoMnN}_{6} \mathrm{O}_{5}, 0.5 \mathrm{C}_{4} \mathrm{H}_{10} \mathrm{O}$ & $\mathrm{C}_{28} \mathrm{H}_{28} \mathrm{CoMnN} \mathrm{N}_{5} \mathrm{O}_{4}, 0.5 \mathrm{C}_{4} \mathrm{H}_{10} \mathrm{O}$ \\
\hline$M_{\mathrm{r}}$ & 661.46 & 652.45 & 649.48 \\
\hline Crystal size (mm) & $0.23 \times 0.19 \times 0.15$ & $0.40 \times 0.32 \times 0.23$ & $0.21 \times 0.17 \times 0.13$ \\
\hline Crystal system & Triclinic & Triclinic & Triclinic \\
\hline Space group & $P \overline{1}$ (no. 2) & $P \overline{1}$ (no. 2) & $P \overline{1}$ (no. 2) \\
\hline$a(\AA)$ & $8.2695(6)$ & $8.4721(6)$ & $8.2077(11)$ \\
\hline$b(\AA)$ & $9.7088(7)$ & $11.6683(8)$ & $14.0954(18)$ \\
\hline$c(\AA)$ & $18.2274(13)$ & $14.6631(11)$ & $14.480(2)$ \\
\hline$\alpha\left({ }^{\circ}\right)$ & $92.512(6)$ & $99.575(6)$ & $69.134(10)$ \\
\hline$\beta\left(^{\circ}\right)$ & $93.978(6)$ & $91.948(6)$ & $77.764(11)$ \\
\hline$y\left({ }^{\circ}\right)$ & $100.810(6)$ & $100.777(6)$ & $86.881(11)$ \\
\hline$V\left(\AA^{3}\right)$ & $1431.57(18)$ & $1400.94(17)$ & $1529.4(4)$ \\
\hline$\rho_{\text {calcd. }}\left(\mathrm{g} \mathrm{cm}^{-3}\right)$ & 1.535 & 1.547 & 1.410 \\
\hline$Z$ & 2 & 2 & 2 \\
\hline$F(000)$ & 682 & 672 & 672 \\
\hline$\mu\left(\mathrm{mm}^{-1}\right)$ & 1.073 & 1.095 & 0.999 \\
\hline$T_{\max } / T_{\min }$ & $0.8928 / 0.6583$ & $0.7919 / 0.6405$ & $0.9154 / 0.7141$ \\
\hline$h k l$ range & $\pm 9,-11$ to $10, \pm 21$ & $\pm 9, \pm 13, \pm 17$ & -9 to $8, \pm 16, \pm 16$ \\
\hline 0 range $\left({ }^{\circ}\right)$ & $2.14-24.87$ & $1.80-24.86$ & $2.54-24.50$ \\
\hline Measured refl. & 19171 & 18530 & 14512 \\
\hline Unique refl. ( $\left.R_{\mathrm{int}}\right)$ & 4935 & 4800 & 5062 \\
\hline Observed refl. $I>2 \sigma(I)$ & 3955 & 4143 & 3002 \\
\hline Data/restraints/parameter & $4935 / 0 / 381$ & $4800 / 0 / 352$ & $5062 / 0 / 400$ \\
\hline Goodness-of-fit & 1.044 & 1.047 & 1.009 \\
\hline$R_{1}, w R_{2},(I>2 \sigma(I))$ & $0.0331,0.0794$ & $0.0262,0.0698$ & $0.0656,0.1351$ \\
\hline$R_{1}, w R_{2}$ (all data) & $0.0454,0.0825$ & $0.0313,0.0711$ & $0.1297,0.1641$ \\
\hline Resid. el. dens. $\left(\mathrm{e} \AA^{-3}\right)$ & $0.308 /-0.400$ & $0.281 /-0.304$ & $0.942 /-1.357$ \\
\hline
\end{tabular}

program [27]. For the diethyl ether solvent molecule in 4 no satisfactory model for the disorder could be found, and for further refinement the contribution of the missing solvent molecule (213.3 $\AA^{3}$, electron count 43 ) was subtracted from the reflection data by the SQUEEZE [28] routine of the PLATON program [27]. The diethyl ether solvent molecule in 5 was refined at half occupancy.

\section{Acknowledgements}

Support by the Alexander von Humboldt foundation (research fellowship to H.Z.) is gratefully acknowledged. We thank J. Teichgräber for CV measurements.

\section{Appendix A. Supplementary material}

CCDC 631167,631168 and 631169 contain the supplementary crystallographic data for 3, 4 and 5. These data can be obtained free of charge via http://www.ccdc.cam.ac. uk/conts/retrieving.html, or from the Cambridge Crystallographic Data Centre, 12 Union Road, Cambridge CB2 1EZ, UK; fax: (+44) 1223-336-033; or e-mail: deposit@ ccdc.cam.ac.uk. Supplementary data associated with this article can be found, in the online version, at doi: 10.1016/j.jorganchem.2007.03.012.

\section{References}

[1] C. Belle, J.-L. Pierre, Eur. J. Inorg. Chem. (2003) 4137-4146.
[2] (a) R.E. Stenkamp, Chem. Rev. 94 (1994) 715-726, and refernces therein;

(b) A.K. Shiemke, T.M. Loehr, J. Sanders-Loehr, J. Am. Chem. Soc. 108 (1986) 2437-2443.

[3] (a) R. Bosnich, Inorg. Chem. 38 (1999) 2554-2562;

(b) C.J. Qin, A. Gavrilova, B. Bosnich, Pure Appl. Chem. 73 (2001) 221-226.

[4] (a) D.E. Fenton, H. Okawa, Chem. Ber./Recueil 130 (1997) 433-442; (b) D.E. Fenton, Inorg. Chem. Comm. 5 (2002) 537-547.

[5] C. Incarvito, A.L. Rheingold, A.L. Gavrilova, C.J. Qin, B. Bosnich, Inorg. Chem. 40 (2001) 1386-1390.

[6] (a) M. Konrad, F. Meyer, K. Heinze, L. Zsolnai, J. Chem. Soc., Dalton Trans. (1998) 199-205;

(b) M. Konrad, S. Wuthe, F. Meyer, E. Kaifer, Eur. J. Inorg. Chem. (2001) 2233-2240.

[7] A.L. Gavrilova, C.J. Qin, R.D. Sommer, A.L. Rheingold, B. Bosnich, J. Am. Chem. Soc. 124 (2002) 1714-1722.

[8] (a) J.C. Röder, F. Meyer, E. Kaifer, J. Organomet. Chem. 641 (2002) 113-120;

(b) T. Sheng, S. Dechert, A.C. Stückl, F. Meyer, Eur. J. Inorg. Chem. (2005) 1293-1302.

[9] T. Sheng, S. Dechert, I. Hyla-Kryspin, R.F. Winter, F. Meyer, Inorg. Chem. 44 (2005) 3863-3874.

[10] (a) S. Trofimenko, Progr. Inorg. Chem. 34 (1986) 115-210; (b) G. La Monica, G.A. Ardizzoia, Progr. Inorg. Chem. 46 (1997) 151-238;

(c) R. Mukherjee, Coord. Chem. Rev. 203 (2000) 151-218.

[11] C. Tejel, M.A. Ciriano, J.A. López, F.J. Lahoz, L.A. Oro, Angew Chem. 110 (1998) 1647-1650.

[12] T.G. Schenck, C.R.C. Milne, J.F. Sawyer, B. Bosnich, Inorg. Chem. 24 (1985) 2338-2344.

[13] (a) J.C. Röder, F. Meyer, E. Kaifer, Angew. Chem. 114 (2002) 2414 2417;

J.C. Röder, F. Meyer, E. Kaifer, Angew. Chem., Int. Ed. 41 (2002) 2304-2306; 
(b) J.C. Röder, F. Meyer, I. Hyla-Kryspin, R.F. Winter, E. Kaifer, Chem. Eur. J. 9 (2003) 2636-2648.

[14] H. Zhang, S. Dechert, R.F. Winter, F. Meyer, Eur. J. Inorg. Chem., submitted for publication.

[15] K.G. Caulton, Coord. Chem. Rev. 38 (1981) 1-43.

[16] W. Kaim, R. Gross, Comments Inorg. Chem. 7 (1988) 269-285.

[17] T. Nagataki, Y. Tachi, S. Itoh, Chem. Commun. (2006) 4016-4018.

[18] (a) G.B. Deacon, R.J. Phillips, Coord. Chem. Rev. 33 (1980) 227250 ;

(b) V. Robert, G. Lemercier, J. Am. Chem. Soc. 128 (2006) 1183 1187.

[19] Values vs. the ferrocene/ferrocenium couple. $i_{\mathrm{pa}} / i_{\mathrm{pc}}$ close to $1 ; i_{\mathrm{pc}} / v^{1 / 2}$ $\approx$ const; $\Delta E_{\mathrm{p}}=E_{\mathrm{p}}^{\mathrm{ox}}-E_{p}^{\mathrm{red}}=84 \mathrm{mV}$ (3), $90 \mathrm{mV}$ (4), or $88 \mathrm{mV}$ (5) with $\Delta E_{\mathrm{p}}\left(\mathrm{Cp}_{2} \mathrm{Fe} / \mathrm{Cp}_{2} \mathrm{Fe}^{+}\right)=74 \mathrm{mV}$ (3), $74 \mathrm{mV}$ (4), or $64 \mathrm{mV}$ (5) under the same experimental conditions.

[20] R. Gross, W. Kaim, Angew. Chem. 97 (1985) 869-870;

R. Gross, W. Kaim, Angew. Chem., Int. Ed. Engl. 24 (1985) 856-858.
[21] (a) J.P. Bullock, K.R. Mann, Inorg. Chem. 28 (1989) 4006-4011; (b) D.T. Pierce, W.E. Geiger, Inorg. Chem. 33 (1994) 373-381.

[22] It cannot be fully excluded that the reduction is ligand-centered, but the strong dependence of the reduction potential on the coligand (nitrate or acetate, compare Table 3) supports the idea that reduction occurs at the cobalt ion.

[23] N.G. Conelly, W.E. Geiger, Chem. Rev. 96 (1996) 877-910.

[24] M. Kreijcik, M. Daniek, F. Hartl, J. Electroanal. Chem. 317 (1991) 179-187.

[25] G.M. Sheldrick, SHELXL-97, Program for Crystal Structure Refinement, Universität Göttingen, 1997;

G.M. Sheldrick, sHELXs-97, Program for Crystal Structure Solution, Universität Göttingen, 1997.

[26] STOE \& CIE GmbH, X-RED, Darmstadt, 2002.

[27] A.L. Spek, PLATON, A Multipurpose Crystallographic Tool, Utrecht University, 2003.

[28] P.v.d. Sluis, A.L. Spek, Acta Crystallogr., Sect. A 46 (1990) 194-201. 